\title{
Growth and Fruit Quality of 'Kyoho' Grapevines Grafted on Autotetraploid Rootstocks
}

\author{
Hino Motosugi*, Yasuhisa Yamamoto, Takasumi Naruo and Daisuke Yamaguchi \\ University Farm, Kyoto Prefectural University, Oji, Kitaina-Yazuma, Seika-Cho, Kyoto 619-0244, Japan
}

The growth of 'Kyoho' (Vitis $\times$ labruscana Bailey $\times V$. vinifera L.) grapevines grafted on colchicine-induced autotetraploids of two grape rootstocks, 'Riparia Gloire de Montpellier' ('Gloire', V. riparia Michx.), and 'Couderc 3309' ('3309', $V$. riparia $\times V$. rupestris), was compared with the original diploids. Micro-propagated rootstock and 'Kyoho' grapevines were grafted in vitro and rooted. During the rooting and acclimating stage, 'Kyoho' grapevines grafted on tetraploids had much shorter shoots and internodes than those grafted on the counterpart diploids. In the nursery period in pots, 'Kyoho' grapevines grafted on each tetraploid rootstock also showed weaker growth than those grafted on the corresponding diploid rootstock. After planting in the vineyard, lateral shoot growth after primary shoot-tipping, the trunk cross-sectional area and pruned cane weight of ' $K y o h o '$ grapevines grafted on each tetraploid rootstock were also smaller than those grafted on the corresponding diploid rootstock. The berries of 'Kyoho' grapevines grafted on tetraploids showed much deeper skin coloration than those of vines grafted on diploid rootstocks.

Key Words: berry quality, grape rootstock, micrografting, scion vigor, tetraploid rootstock.

\section{Introduction}

Large-berry tetraploid grape cultivars such as 'Kyoho' and 'Pione' have been planted in about $43 \%$ of the total grape production area in Japan (Production and Shipment of Grapes and Japanese Pears. 2005, Ministry of Agriculture, Forestry and Fishery of Japan). These cultivars grafted on common rootstocks (diploids) grow vigorously, and often show flower shattering. In addition, the vigorous roots are likely to absorb nitrogen constantly in summer, which seems to be related to poor berry coloration. The continuous supply of a high level of nutrient solution resulted in poorly colored and highly acidic berries on 'Kyoho' grapevines (Okamoto et al., 1991). To establish quality berries of tetraploid grape cultivars, many cultural practices such as flower thinning, fruit cluster thinning, shoot tipping, and the application of growth-regulative chemicals are needed.

Received; July 22, 2006. Accepted; March 25, 2007.

A part of this study was presented at the 1999 Autumn Meeting, 2000 Autumn Meeting, 2001 Spring Meeting, 2002 Kinki Chapter Meeting, 2003 Spring Meeting, and 2004 Autumn Meeting of the Japanese Society for Horticultural Science.

This work was partially supported by a Grant-in Aid for the Encouragement of Young Scientists (A) (No. 09760028) from the Ministry of Education, Science, Sports and Culture, Japan.

* Corresponding author (E-mail: motosugi@kpu.ac.jp).
Therefore, control of the vigor of tetraploid grape cultivars by appropriate dwarfing rootstocks could improve berry quality.

In grapevines and several fruit trees such as Japanese persimmon and satsuma mandarin, restriction of the root zone has been using practically in commercial culture to regulate scion vigor and improve fruit quality (Imai, 2001; Imai et al., 1987; Matsumura, 2001; Sawano, 2001). Tetraploid grapevines such as 'Pione' grown in the restricted root zone produced a larger number of seeded berries than grapevines whose roots extended freely (Okamoto and Imai, 1989). Therefore, a rootstock with root growth restricted naturally without barriers like the artificially restricted root-zone culture, if any, could appropriately regulate scion vigor and consequently improve setting and coloration of berries.

Own-root systems of tetraploid grapevines are relatively weak and compact compared with the original diploids (Motosugi, 2000; Olmo, 1976). Imai et al. (1987) also reported that own-rooted 'Kyoho' and 'Pione' grapevines showed better berry setting than grapevines grafted on 'Teleki 8B' rootstocks. This improvement of berry setting is thought to relate to the phenomenon that own-root systems of 'Kyoho' and 'Pione' are tetraploid. In a previous study, tetraploids of three grapevine rootstocks ('Gloire', '3309', and 'St. George'), produced by in vitro colchicine treatment, had 
relatively thicker and shorter roots than the original diploid rootstocks, the root system of tetraploids being very compact (Motosugi et al., 2002b). Due to such characteristics of the root system, the tetraploid rootstock may reduce the growth of the scion grafted on it compared to the original diploid rootstock. In this study, the effect of tetraploid rootstocks on the growth and berry quality of 'Kyoho' grapevines grafted on them was compared with those of the original diploid rootstocks in the nursery period and for the first several years in the vineyard.

\section{Materials and Methods}

Preparation of grafted grapevines from in vitro culture

A weak rootstock 'Gloire' and a vigorous rootstock '3309' (Galet, 1979) were used in this experiment. Colchicine-induced autotetraploids, 'Gloire' $(4 \mathrm{x})$, and ' 3309 ' (4x), and the original diploids, were micropropagated successively in rooting medium (Motosugi et al., 2002b), which consisted of Murashige and Skoog (MS) salts (Murashige and Skoog, 1962) with 1/3 nitrogen containing $3 \%$ sucrose, $0.8 \%$ agar and $0.5 \mu \mathrm{M}$ 1-naphthaleneacetic acid (NAA). A simple cutting-graft method was used for micrografting because this technique is very easy and it takes a short time to establish grafted plantlets (Motosugi and Naruo, 1999). Internode segments $(1.5-2.0 \mathrm{~cm})$ were dissected from the shoots of each tetraploid and diploid rootstock, and $0.5 \mathrm{~cm}$ in length from the upper end was cut longitudinally. A tetraploid scion cultivar 'Kyoho' was also micropropagated in rooting medium. One-node segments $(0.5-$ $1.0 \mathrm{~cm}$ ) without leaves were dissected from 'Kyoho' shoots, and the basal end of each segment was cut into a wedge form. The wedge-formed end of the segment of the 'Kyoho' scion was inserted into the cut end of the internode segment of the rootstock (cleft grafting). The basal end of these grafted scion-rootstock cuttings was put in the rooting medium $0.5 \mathrm{~cm}$ in depth. Two grafted cuttings were placed on $40 \mathrm{~mL}$ solid medium in a $200 \mathrm{~mL}$ glass bottle with a transparent plastic cap.

\section{Growth in the acclimation stage}

Six weeks after grafting, micrografted cuttings were transplanted into a polyethylene pot $(9 \mathrm{~cm}$ in diameter) filled with vermiculite and placed on a light shelf covered with transparent polyethylene film to maintain moisture. Nutrient solution $(\mathrm{N}: \mathrm{P}: \mathrm{K}=18.6: 1.7: 8.6 \mathrm{mM}$ ) was applied biweekly. Two months after transplanting, the shoot length and number of nodes of 'Kyoho' grapevines grafted on each rootstock were measured and data for statistic analysis were collected from 11-20 grapevines showing superior growth on each rootstock. Both in micrografting and acclimation experiments, environmental conditions were $50 \mu \mathrm{mol} \cdot \mathrm{m}^{-2} \cdot \mathrm{s}^{-1}$ of light intensity, 16-h day length, and $25 \pm 1^{\circ} \mathrm{C}$.
Growth in the second year after acclimation

'Kyoho' grapevines micrografted on 'Gloire', '3309', 'Gloire' (4x), and '3309' (4x) acclimated on the light shelf were transferred to a glasshouse and transplanted into a larger polyethylene pot $(18 \mathrm{~cm}$ in diameter) filled with vermiculite: perlite $(1: 1)$ medium. Five grams of mixed-coating fertilizer $(\mathrm{N} 0.63 \mathrm{~g}, \mathrm{P} 0.16 \mathrm{~g}, \mathrm{~K} 0.36 \mathrm{~g}$, $\mathrm{Ca} 0.27 \mathrm{~g}, \mathrm{Mg} 0.04 \mathrm{~g}$ ), which could constantly release these elements for 100 days, was scattered on the pot surface. In late autumn, grapevines grown in the greenhouse were pruned to $30 \mathrm{~cm}$ in height and transferred outside for chilling. The next spring (March 2000), 20 to 30 'Kyoho' grapevines grafted on each rootstock were transplanted to larger pots $(30 \mathrm{~cm}$ in diameter) filled with sandy soil: sawdust manure $(4: 1)$ and transferred to a rain-shelter plastic house. Ten grams of mixed-coating fertilizer was scattered on the pot surface every two months. Water was supplied automatically twice a day. Only one shoot at the top node of the grapevine was left; all other shoots were removed and all lateral shoots were trimmed at one node. The shoots were trained vertically up to $1.5 \mathrm{~m}$ in height, then horizontally, and tipped when the node number increased to $40-45$ (Fig. 1). Shoot length and the number of nodes were measured biweekly from early May to September. After leaf fall, stem diameter in the thickest and thinnest directions was measured at the second or third internode above the graft union and the crosssectional area was calculated, assuming that the stem cross-section was a true oval. Ratios of mature nodes to all nodes of shoots were also determined. Each 10 grapevines grafted on tetraploids or original rootstocks were dug from pots and washed with water. Root volume was calculated from the difference between the weight of the plant and that of the plant with roots submerged in water.

\section{Growth, berry set and berry quality in the vineyard}

The grapevines were removed from pots with medium and transplanted into the vineyard in late March 2001. Four grapevines of each rootstock were planted at $1.5 \mathrm{~m}$ intervals in a straight row with a random design. The cane was pruned at $2.0 \mathrm{~m}$ in length and bent horizontally at $1.5 \mathrm{~m}$ height along a horizontal trellis system (Fig. 1). The shoots emerging from the cane on the horizontal trellis were allowed to grow freely on the trellis without any shoot pruning. Flower clusters were thinned to a single cluster per each shoot but berries were not thinned after fruit set because the numbers of florets were relatively few. Fruit clusters were harvested on 20 August. In winter, grapevines were pruned, leaving two $2.5 \mathrm{~m}$ canes, which were trained in a U-shape (Fig. 1).

In the following season (2002), 20-25 shoots per vine emerging from the distal $1.3 \mathrm{~m}$ part of each cane were left and trained parallel to the horizontal trellis. Before anthesis, shoots were tipped at the approximately 15 th node and the lateral shoots were pruned to leave the first 


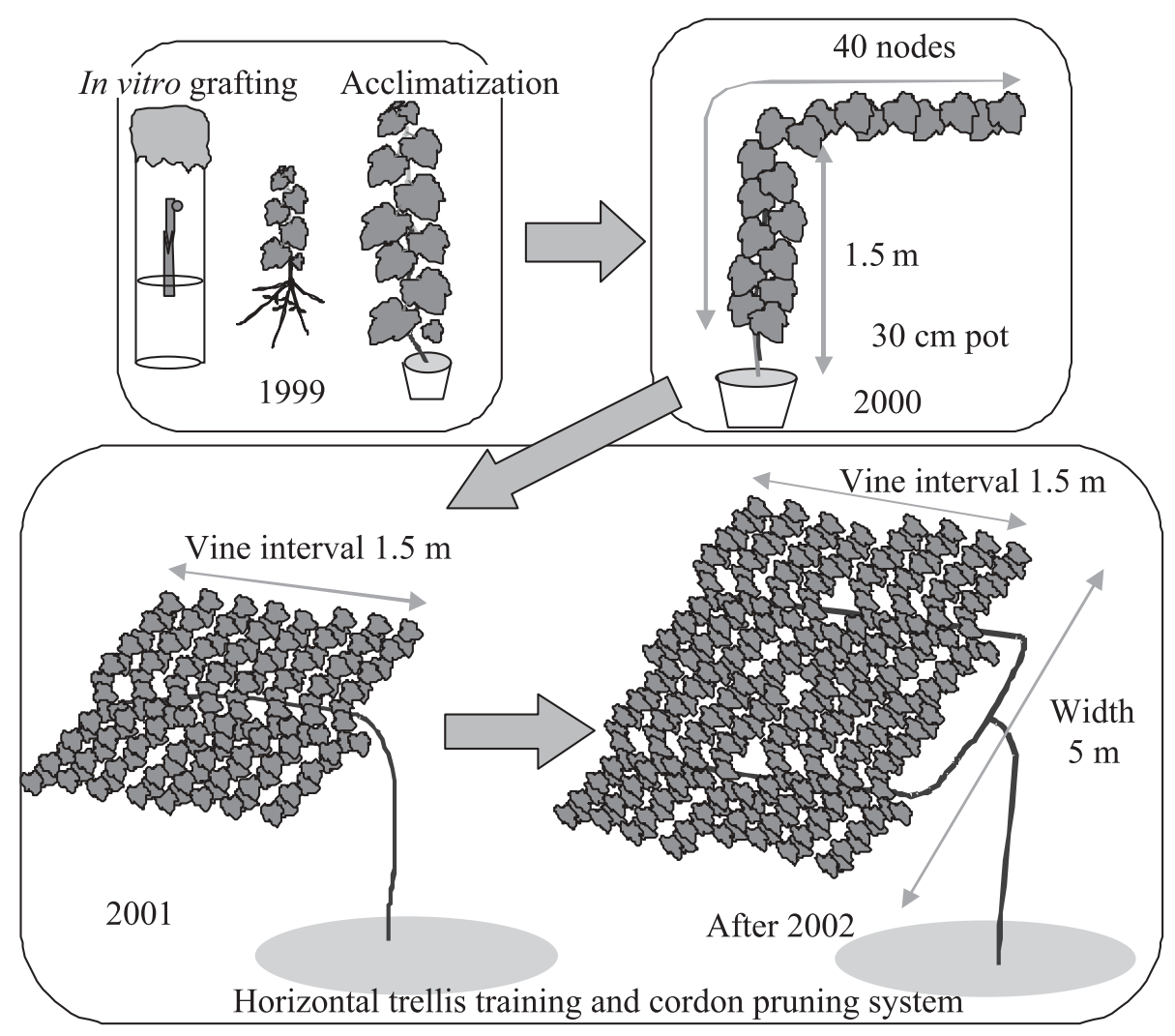

Fig. 1. Illustration of growing and training system of 'Kyoho' grapevines in this experiment.

leaf. Flower clusters were thinned to a single cluster per shoot and shaped in the conventional way. At full bloom, 5 clusters per vine in 2002 or 10 clusters per vine in 2003 were covered with a paper bag to collect florets and fruitlets dropped from the cluster. Two weeks after bagging, the number of fruitlets attached to a cluster, and that of florets and fruitlets dropped into the paper bag were counted. The lateral shoots, which grew after anthesis, were repeatedly pruned, leaving one or two leaves, on 10 June, 18 July and 21 September, and the pruned shoots were weighed. Fruit clusters were harvested on 21st August. All canes were pruned to 2 nodes on each cordon in winter. In 2003, shoot and cluster management was the same as the previous year and fruit clusters were harvested on 2 September.

The harvested clusters were weighed and five representative berries were collected from each cluster and weighed. For the determination of berry quality, 5 berries per cluster were selected from all clusters in the first season and three representative clusters in the following seasons. To measure skin coloration, five skin disks ( $8 \mathrm{~mm}$ in diameter) were sampled from the equator portion of the individual berries and put into $10 \mathrm{~mL}$ of $\mathrm{MeOH}$ containing $1 \% \mathrm{HCl}$, held in refrigerator at $4{ }^{\circ} \mathrm{C}$ for $24 \mathrm{~h}$, and the optical density of the extract was measured at $530 \mathrm{~nm}$ using a spectrophotometer. The peeled berries were squeezed and the total soluble solids content of the juice was measured using a refractometer, and acidity was titrated with $0.05 \mathrm{~N} \mathrm{NaOH}$ solution.
The trunk cross-sectional area $30 \mathrm{~cm}$ above the graft union and the weight of pruned canes were measured after leaf fall every season. In order to evaluate the efficiency of rootstocks as the control factor for the source/sink relationship, yield efficiency was calculated by dividing total cluster weight per vine by trunk crosssectional area (Battilani, 2000; Battilani and Mannini, 2000).

The mixed-coating fertilizer $(200 \mathrm{~g} / \mathrm{vine})$, with the same composition as mentioned in the previous section, was scattered around the trunk in a circle $50 \mathrm{~cm}$ in diameter three times (April, July, and October) in 2001 and 2002, and twice (April and October) in 2003. Other cultivation practices, e.g. pest management, were carried out by the conventional method.

\section{Statistics}

In the stages of acclimation and growth in a pot $30 \mathrm{~cm}$ in diameter, mean differences were analyzed by $t$-test between diploids and tetraploids of each rootstock because the replications of each rootstock were different. In the vineyard experiments, two-way analysis of variance (Rootstock $\times$ Ploidy) was conducted. Percentage values were subjected to arc-sin transformation before statistical analyses. 


\section{Results}

\section{Growth of micrografted grapevines in rooting and} acclimation stage

The percentage of successful grafting was over $90 \%$ in most scion-rootstock combinations. In rooting culture, the tetraploid rootstocks had a significantly shorter average root length than the original diploid rootstocks (Table 1). In the acclimation stage, the scions grafted on tetraploid rootstocks showed significantly poorer growth than those grafted on the original diploid (Table 1). The reduction of scion growth by grafting on tetraploid rootstock compared to the original diploid rootstock was greater in 'Gloire' (4x) than in '3309' (4x).

\section{Growth in the second year after acclimation}

The shoots of 'Kyoho' grapevines grafted on '3309' $(4 \mathrm{x})$ and 'Gloire' $(4 \mathrm{x})$ elongated less vigorously than those grafted on the original diploid rootstocks. As the shoots were tipped when the node number increased to 40-45 nodes, shoot lengths between '3309' and '3309' $(4 \mathrm{x})$ rootstocks were slightly different at the end of the season, but those grafted on 'Gloire' (4x) were significantly shorter (Table 2). The grapevines grafted on tetraploids had shorter internodes than those on diploid rootstocks, and the difference was larger between 'Gloire' and 'Gloire' (4x). The stem cross-sectional areas of 'Kyoho' grapevines grafted on '3309' (4x) and 'Gloire' ( $4 \mathrm{x})$, were also significantly smaller than those grafted on '3309' and 'Gloire'.

There were no differences in the ratio of mature shoots in any scion-rootstock combinations (Table 2). The total vine weight and root volume of 'Kyoho' grapevines on tetraploid rootstocks were significantly smaller than those grafted on the original diploid rootstocks, and those of grapevines grafted on '3309' were the largest (Table 2). Fine roots of tetraploid rootstocks were thicker and shorter than those of diploid rootstocks, and the appearance of root systems of tetraploid rootstocks was more coarse (data not shown).

\section{Growth in the vineyard, and berry set and quality}

The trunk cross-sectional area and pruning weight of 'Kyoho' grapevines increased year by year and were larger on diploid rootstocks than on tetraploid rootstocks (Fig. 2). Furthermore, 'Gloire' rootstocks induced less growth than '3309'. Lateral shoot growth of 'Kyoho' grapevines grafted on tetraploid rootstocks was much weaker than those grafted on diploids (Fig. 3). There was no significant difference in berry set among ploidy in 2002 but tetraploid rootstocks reduced berry set in both rootstock cultivars in 2003 (Table 3). The number of berries per cluster two weeks after full bloom was also considerably fewer than the recommended number of berries per cluster after final thinning, 30 to 35 berries, described in the common practical guidance. (Table 3). Fruit production increased year by year and yield efficiency (crop load per trunk cross-sectional area) tended to be higher on tetraploid rootstocks (Fig. 4) but there were no significant differences in yield per vine and yield efficiency among rootstocks and ploidy as a result of 2-way analysis of variance in the data of each year.

In 2001, there were only a few shoots bearing flower

Table 1. Growth of 'Kyoho' grapevines micrografted on '3309', 'Gloire', and their tetraploids in rooting culture and during acclimation stage.

\begin{tabular}{lccccccc}
\hline \hline \multirow{2}{*}{ Rootstock } & \multicolumn{9}{c}{ Rooting culture $^{\mathrm{x}}$} & & \multicolumn{2}{c}{ Acclimation stage $^{\mathrm{y}}$} \\
\cline { 2 - 5 } \cline { 6 - 8 } & $\begin{array}{c}\text { Shoot length } \\
(\mathrm{cm})\end{array}$ & $\begin{array}{c}\text { Internode length } \\
(\mathrm{cm})\end{array}$ & $\begin{array}{c}\text { Number of roots per } \\
\text { plants }\end{array}$ & $\begin{array}{c}\text { Mean root length } \\
(\mathrm{cm})\end{array}$ & & $\begin{array}{c}\text { Shoot length } \\
(\mathrm{cm})\end{array}$ & $\begin{array}{c}\text { Internode length } \\
(\mathrm{cm})\end{array}$ \\
\hline 3309 & $7.8 \mathrm{NS}^{\mathrm{x}}$ & $1.2 \mathrm{NS}$ & $5.9^{*}$ & $6.8^{* *}$ & $86.3^{* * *}$ & $4.0^{* * *}$ \\
$3309(4 \mathrm{x})$ & 7.3 & 1.1 & 4.6 & 5.2 & 63.8 & 3.4 \\
Gloire & $8.5 \mathrm{NS}$ & $1.5 \mathrm{NS}$ & $8.9 \mathrm{NS}$ & $6.8^{* * *}$ & $84.1^{* * *}$ & $4.1^{* * *}$ \\
Gloire $(4 \mathrm{x})$ & 6.7 & 1.3 & 7.7 & 3.4 & 55.8 & 3.2 \\
\hline
\end{tabular}

${ }^{z}$ Measurements were made after 6 weeks of micrografting. $(n=11-36)$.

${ }^{y}$ Measurements were made after 2-month acclimation period. $(n=11-20)$.

${ }^{\times} t$-test between diploid and tetraploid of each rootstock, NS: not significant, *, **, ***: significant at $P<0.05,0.01$, and 0.001 , respectively.

Table 2. Shoot growth and root volume of 'Kyoho' grapevines grafted on '3309', 'Gloire', and their tetraploids grown in 30-cm pot.

\begin{tabular}{|c|c|c|c|c|c|c|}
\hline & $\begin{array}{l}\text { Shoot length }{ }^{2} \\
(\mathrm{~cm})\end{array}$ & $\begin{array}{c}\text { Internode length } \\
(\mathrm{cm})\end{array}$ & $\begin{array}{c}\text { Total vine weight } \\
\text { (g) }\end{array}$ & $\begin{array}{c}\text { Ratio of mature nodes } \\
(\%)\end{array}$ & $\begin{array}{l}\mathrm{SCSA}^{y} \\
\left(\mathrm{~cm}^{2}\right)\end{array}$ & $\begin{array}{l}\text { Root volume } \\
\quad\left(\mathrm{cm}^{3}\right)\end{array}$ \\
\hline 3309 & $317.0^{* \mathrm{x}}$ & $7.1 * * x$ & $745.4 \mathrm{NS}^{\mathrm{w}}$ & $91.3 \mathrm{NS}^{\mathrm{x}}$ & $1.42 * * x$ & $422.8^{* * w}$ \\
\hline $3309(4 x)$ & 295.4 & 6.4 & 502.1 & 88.5 & 1.08 & 284.0 \\
\hline Gloire & $317.4 * * *$ & $6.9 * * *$ & $595.8^{* * *}$ & $88.1 \mathrm{NS}$ & $1.25^{* * *}$ & $342.1 * * *$ \\
\hline Gloire $(4 x)$ & 228.6 & 5.6 & 299.9 & 83.4 & 0.60 & 193.1 \\
\hline
\end{tabular}

${ }^{z}$ All vines were tipped at the $40-45$ th node.

y Stem cross-sectional area.

${ }^{x} t$-test within each rootstock $(\mathrm{n}=20-31)$, NS: not significant, $*, * *, * * *$ : significant at $P<0.05,0.01$, and 0.001 , respectively.

${ }^{\mathrm{w}} t$-test within each rootstock $(\mathrm{n}=10)$, NS: not significant, ${ }^{*}, * *, * * *$ : significant at $P<0.05,0.01$, and 0.001 , respectively. 

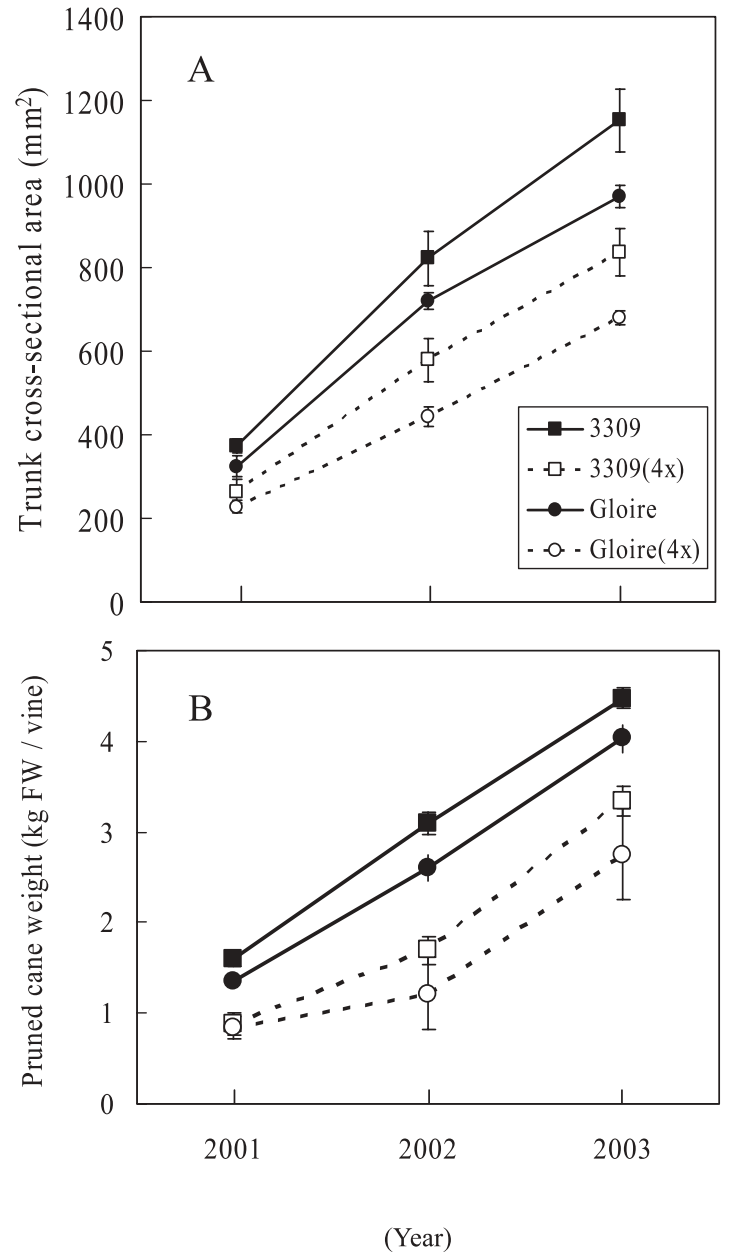

Fig. 2. Changes in trunk cross-sectional area (A) and pruned cane weight (B) of 'Kyoho' grapevines grafted on '3309', 'Gloire', and their tetraploids. Vertical bars show SE $(n=4)$.

clusters and the average number of fruit clusters per vine was 2 to 3 . Therefore, no statistical analysis was done, though the skin color content of the berries on 'Kyoho' grapevines grafted on tetraploid rootstocks tended to be higher than on diploid rootstocks (unpublished data). In both 2002 and 2003, the skin color of 'Kyoho' grapes

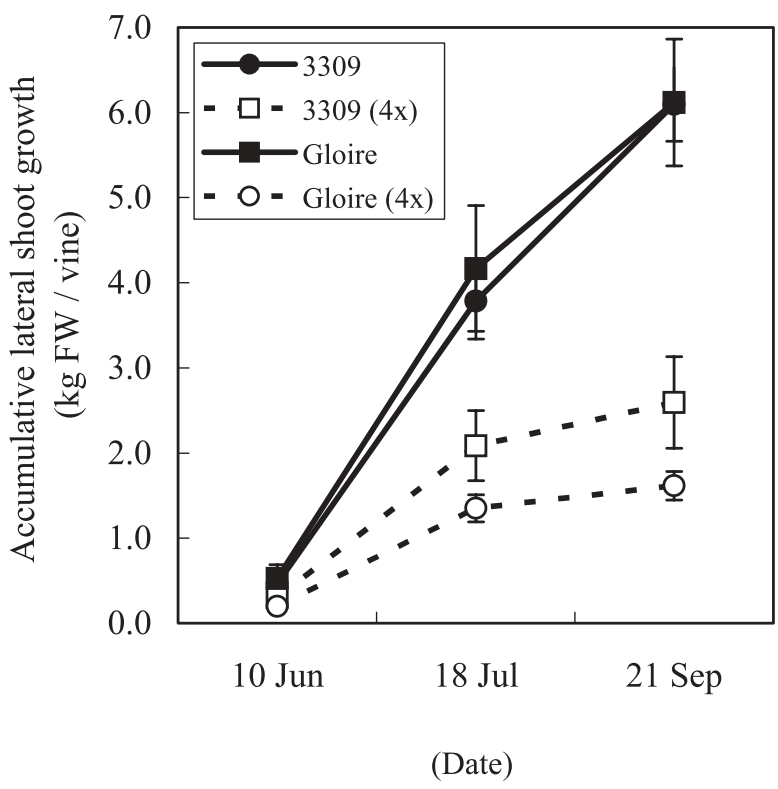

Fig. 3. Accumulative weight of lateral shoots pruned monthly of 'Kyoho' grapevines grafted on '3309', 'Gloire', and their tetraploids. Data were collected in 2002. Vertical bars show SE $(\mathrm{n}=4)$.

on tetraploid rootstocks was significantly deeper than on diploid rootstocks (Table 4). The juice acidity of 'Kyoho' grapes on tetraploid rootstocks was significantly lower in 2003 than that on diploids. Comparing two rootstock cultivars, 'Gloire' rootstock produced the berries with deeper skin color, higher sugar content and lower acidity than '3309' rootstock (Table 4).

\section{Discussion}

All common grapevine rootstocks are diploid. In Vitis species used as grape rootstocks, some tetraploids have been reported (Staudt, 1995; Tompson and Olmo, 1963) but there have been no reports on the performance of tetraploid rootstocks. In this report, new tetraploids of 'Gloire' and '3309' produced by colchicine treatment for micropropagating plantlets were demonstrated to reduce the vegetative growth of scions grafted on them compared to those grafted on the original diploid

Table 3. Berry number per cluster and berry set (\%) measured 2 weeks after full bloom of 'Kyoho' grapevines grafted on '3309', 'Gloire', and their tetraploids grown in vineyard.

\begin{tabular}{|c|c|c|c|c|c|}
\hline \multirow{2}{*}{ Rootstock } & \multirow{2}{*}{ Ploidy } & \multicolumn{2}{|c|}{ Berry number per cluster } & \multicolumn{2}{|c|}{ Berry set $(\%)$} \\
\hline & & 2002 & 2003 & 2002 & 2003 \\
\hline \multirow[t]{2}{*}{3309} & $2 \mathrm{x}$ & 12.4 & 27.8 & 6.2 & 22.4 \\
\hline & $4 \mathrm{x}$ & 10.2 & 21.6 & 4.8 & 16.6 \\
\hline \multirow[t]{2}{*}{ Gloire } & $2 \mathrm{x}$ & 15.2 & 27.9 & 9.4 & 22.4 \\
\hline & $4 \mathrm{x}$ & 14.7 & 17.7 & 10.8 & 12.9 \\
\hline \multicolumn{6}{|l|}{$\mathrm{ANOVA}^{\mathrm{z}}$} \\
\hline Rootstock & & NS & NS & $*$ & NS \\
\hline Ploidy & & NS & NS & NS & $*$ \\
\hline Interaction & & NS & NS & NS & NS \\
\hline
\end{tabular}

${ }^{\text {z }}$ NS: not significant, *: significant at $P<0.05(\mathrm{n}=20$ in 2002 or 40 in 2003). 

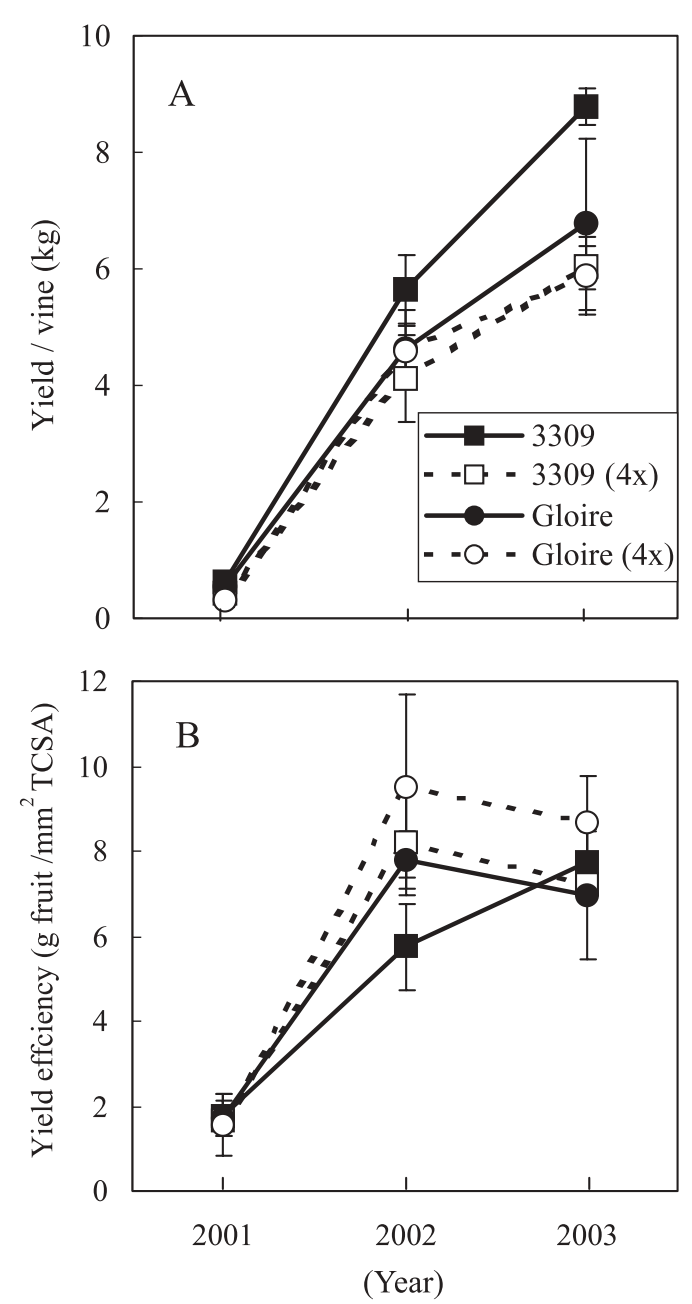

Fig. 4. Changes in yield per vine (A) and yield efficiency (yield/trunk cross-sectional area) (B) of 'Kyoho' grapevines grafted on '3309', 'Gloire', and their tetraploids. Vertical bars show SE $(\mathrm{n}=4)$.

rootstocks. There are some reports about using tetraploids as rootstocks controlling scion vigor in citrus and apple trees. Lee (1988) reported that autotetraploids of commercial citrus rootstocks reduced the scion size. Grosser and Chandler (2000) also reported that a somatic hybrid (allotetraploid) between sour orange and 'Palestine' sweet lime reduced the scion size of sweet orange. Beakbane (1967) reported a tetraploid chimera of M.13 apple rootstock that was about as dwarfing as M.9. Thus, polyploidized rootstocks in these fruit trees and grapevines may have common activity in controlling scion vigor.

Among diploid rootstocks, '3309' is a vigorous rootstock, but 'Gloire' is weak, and its lack of vigor favors quality over quantity and hastens ripening (Galet, 1979). Delas et al. (1991) reported that 'Merlot' grapevines grafted on 'Gloire' had lower pruning weight and yield, but higher sugar content of must and total phenolic compounds in skin than grapevines grafted on '3309'. Similar relationships between 'Gloire' and '3309' rootstocks were shown in our experiment using
'Kyoho' scions. Moreover, the relationship of scion vigor between these two tetraploid rootstocks was similar to between the original diploid rootstocks, that is, 'Kyoho' grapevines grafted on 'Gloire' $(4 \mathrm{x})$ showed smaller growth but higher sugar content of juice and skin anthocyanin content than vines grafted on '3309' (4x).

Autotetraploid rootstocks have similar resistance to phylloxera compared with the original diploid rootstocks (Motosugi et al., 2002a) but much thicker and shorter roots than the original diploids, and their root system is very coarse and compact (Motosugi et al., 2002b). These characteristics of the roots of tetraploid rootstocks may reduce water and nutrients absorption of 'Kyoho' grapevines. We reported that tetraploid rootstocks, 'Gloire' (4x) and '3309' (4x), showed much lower flow rate of bleeding sap from a stem stump than the original diploid rootstocks (Motosugi and Yamamoto, 2000). We observed the reduced size of the leaves of 'Kyoho' on vines grafted on tetraploid rootstock (Motosugi and Yamamoto, 2000), which might similarly have resulted from water stress (Reynolds and Naylor, 1994). The lower transpiration and net photosynthetic rates on 'Kyoho' grapevines grafted on the tetraploid rootstock (Motosugi and Yamamoto, 2004) should also result from water stress. Stem water potential of 'Kyoho' grapevines grafted on tetraploids measured at midday was significantly lower than that of vines grafted on the original diploids (Yamaguchi and Motosugi, 2004). Matthews and Anderson (1988) reported that moderate water stress in the berry ripening stage enhanced berry coloring. For grapevines growing in dry areas, regulated deficit irrigation (RDI) and partial rootzone drying (PRD) were introduced to improve berry quality (Behboudian and Singh, 2001; Goodwin and Macrae, 1990; McCarthy et al., 2002). PRD reduced vegetative growth but increased water use efficiency and light penetration into the canopy, resulting in high berry quality (Dos Santos et al., 2003; McCarthy et al., 2002). In our experiment, the reduced vegetative growth of 'Kyoho' grapevines grafted on tetraploid rootstocks may also increase berry quality as above, probably from moderate water stress due to compact and the coarse root system of tetraploid rootstocks. We have been investigating the effect of tetraploid rootstocks on water relationships and berry-ripening physiology, and will explain the result in another report.

Tetraploid table grapevines such as 'Kyoho' and 'Pione' usually grafted on the common diploid rootstocks show vigorous shoot growth, which cause problems in fertility and berry coloring. Imai et al. (1987) reported that own-rooted 'Kyoho' and 'Pione' grapevines set many seeded berries but vines grafted on 'Teleki 8B' rootstocks set many seedless berries due to decreases in the penetration and elongation rates of the pollen tube after pollination. Okamoto et al. (2001) reported that vigorous shoot growth of a tetraploid grape cultivar 'Pione' inhibited the development of transmitting tissue 
Table 4. Berry quality of 'Kyoho' grapevine grafted on '3309', 'Gloire', and their tetraploids grown in vineyard.

\begin{tabular}{|c|c|c|c|c|c|c|c|}
\hline \multirow[t]{2}{*}{ Rootstock } & \multirow[t]{2}{*}{ Ploidy } & Cluster weight $(\mathrm{g})$ & $\begin{array}{c}\text { Number of cluster } \\
\text { per vine }\end{array}$ & Berry weight (g) & $\begin{array}{l}\text { Soluble solids } \\
\text { (Brix) }\end{array}$ & $\begin{array}{c}\text { Titratable acids } \\
\text { (\% as tartaric acid) }\end{array}$ & $\begin{array}{c}\text { Anthocyanin } \\
(\mathrm{OD} \text { at } 530 \mathrm{~nm})^{\mathrm{z}}\end{array}$ \\
\hline & & \multicolumn{6}{|c|}{2002} \\
\hline \multirow[t]{2}{*}{3309} & $2 \mathrm{x}$ & 220.0 & 27.0 & 15.0 & 16.7 & 0.61 & 0.163 \\
\hline & $4 \mathrm{x}$ & 183.8 & 23.0 & 15.0 & 16.1 & 0.56 & 0.263 \\
\hline \multirow{2}{*}{ Gloire } & $2 \mathrm{x}$ & 214.1 & 23.0 & 15.1 & 17.4 & 0.57 & 0.212 \\
\hline & $4 \mathrm{x}$ & 206.2 & 23.0 & 14.6 & 17.3 & 0.57 & 0.407 \\
\hline \multicolumn{8}{|l|}{ ANOVA } \\
\hline Rootstock & & $\mathrm{NS}^{\mathrm{y}}$ & NS & NS & $* *$ & NS & $* *$ \\
\hline Ploidy & & NS & NS & NS & NS & NS & $* * *$ \\
\hline \multirow[t]{2}{*}{ Interaction } & & NS & NS & NS & NS & NS & NS \\
\hline & & \multicolumn{6}{|c|}{2003} \\
\hline \multirow[t]{2}{*}{3309} & $2 \mathrm{x}$ & 186.4 & 47.3 & 15.0 & 17.4 & 0.73 & 0.246 \\
\hline & $4 \mathrm{x}$ & 173.3 & 35.0 & 15.5 & 17.5 & 0.67 & 0.372 \\
\hline \multirow[t]{2}{*}{ Gloire } & $2 \mathrm{x}$ & 170.1 & 39.0 & 14.7 & 18.1 & 0.70 & 0.338 \\
\hline & $4 \mathrm{x}$ & 159.8 & 36.5 & 15.9 & 18.4 & 0.65 & 0.486 \\
\hline \multicolumn{8}{|l|}{ ANOVA } \\
\hline Rootstock & & NS & NS & NS & $* * *$ & $*$ & $* *$ \\
\hline Ploidy & & NS & NS & $*$ & NS & $* * *$ & $* * *$ \\
\hline Interaction & & NS & NS & NS & NS & NS & NS \\
\hline
\end{tabular}

${ }^{z}$ Five skin discs $(8 \mathrm{~mm}$ in diameter $) / 100 \mathrm{~mL} 1 \% \mathrm{HCl}-\mathrm{MeOH}$.

y NS: not significant, $*{ }^{* *}$ and $* * *$ : significant at $P<0.05,0.01$, and 0.001 , respectively.

(TT) and pollen tube growth in pistils, resulting in severe flower shuttering or the set of shot berries (small seedless berries). On the other hand, less vigorous shoots grown in the restricted root-zone showed better TT development and allowed for more pollen penetration into the ovary, resulting in the production of acceptable clusters with a sufficient number of seeded berries (Okamoto et al., 2001). So, we expected that the reduced shoot vigor of 'Kyoho' grapevines grafted on tetraploid rootstocks might induce better fertility. This is why we investigated the performance of tetraploid rootstocks compared with the original diploids in a high density planting system $\left(7.5 \mathrm{~m}^{2}\right.$ per vine), and we expected considerable flower shuttering in 'Kyoho' grapevines, those especially grafted on diploid rootstocks. Contrary to our expectations, tetraploid rootstocks somewhat increased flower shuttering and produced many small seedless berries, which were removed before harvest, resulting in smaller cluster weight (Tables 3 and 4). We estimate that producing seeded berries from 'Kyoho' grapevines will become difficult in this high density planting system as vines age, and therefore, we are currently carrying out an investigation on the effects of rootstock ploidy on the quality of seedless berries produced with gibberellin treatment of flower clusters. We will explain the result in another report.

\section{Literature Cited}

Battilani, A. 2000. Application of the regulated deficit of irrigation to grapevines (Vitis vinifera) in a sub-humid area. Acta Hort. 537: 887-894.

Battilani, A. and P. Mannini. 2000. Grapevine (Vitis vinifera) yield and quality response to irrigation. Acta Hort. 537: 895-902. Beakbane, A. B. 1967. The dwarfing effect of a tetraploid sport of M.XIII apple rootstock. Ann. Rep. East Malling Res. Sta. 1966: 96-97.

Behboudian, M. H. and Z. Singh. 2001. Water relations and irrigation scheduling in grapevine. Hort. Rev. 27: 189-225.

Delas, J., C. Molot and J. P. Soyer. 1991. Effects of nitrogen fertilization and grafting on the yield and quality of the crop of Vitis vinifera L. cv. Merlot. Proc. Int. Symp. in Nitrogen in Grapes and Wine: 242-248.

Dos Santos, T. P., C. M. Lopes, M. L. Rodrigues, C. R. de Souza, J. P. Maroco, J. S. Pereira, J. R. Silvia and M. M. Chaves. 2003. Partial rootzone drying: effects on growth and fruit quality of field-grown grapevines (Vitis vinifera). Funct. Plant Physiol. 30: 663-671.

Galet, P. 1979. A practical ampelography: grapevine identification. Cornell Univ. Press, New York.

Goodwin, I. and I. Macrae. 1990. Regulated deficit irrigation of Cabernet Sauvignon grapevine. Aust. \& New Zealand Wine Industry J. 5: 131-133.

Grosser, J. W. and J. L. Chandler. 2000. Somatic hybridization of high yield, cold-hardy and disease resistant parents for citrus rootstock improvement. J. Hort. Sci. Biotech. 75: 641-644.

Imai, S. 2001. Regulation of growth by restricting root zone of fruit trees. I. Characteristics of growth and regulation of tree vigor in tetraploid grapes. Reg. Plant Growth Develop. 36: 159-165 (In Japanese).

Imai, S., G. Okamoto and M. Endo. 1987. Effects of dense planting and root-system control on attaining greater early production and fruit stability of tetraploid grapes. Bull. Hiroshima Fruit Tree Expt. Sta. 12: 1-9 (In Japanese with English abstract).

Lee, L. S. 1988. Citrus polyploidy - Origins and potential for cultivar improvement. Aust. J. Agric. Res. 39: 735-747.

Matsumura, H. 2001. Regulation of growth by restricting root zone of fruit trees. II. Container planting cultivation of Japanese persimmon (Diospyros kaki Thunb.). Reg. Plant 
Growth Develop. 36: 166-172 (In Japanese).

Matthews, M. A. and M. M. Anderson. 1988. Fruit ripening in Vitis vinifera L.: Responses to seasonal water deficits. Amer. J. Enol. Viticul. 39: 313-320.

McCarthy, M. G., B. R. Loveys, P. R. Dry and M. Stoll. 2002. Regulated deficit irrigation and partial root zone drying as irrigation management techniques for grapevines. FAO Water Report 22: 79-87.

Motosugi, H. 2000. Growth comparison between own-rooted of Portland, Niagara, and Campbell Early vines and their tetraploid sports. J. ASEV Jpn. 11: 8-14 (In Japanese with English abstract).

Motosugi, H. and T. Naruo. 1999. Study on the micrografting methods for growth measurement of the grapevines grafted on tetraploid rootstocks. Bull. Exp. Farm Fac. Agri. Kyoto Pref. Univ. 19: 5-8 (In Japanese).

Motosugi, H., T. Naruo, S. Komazaki and M. Yamada. 2002a. Resistance of autotetraploids of grapevine rootstock cultivars to phylloxera (Daktulosphaira vitifoliae [FITCH]). Vitis 41: 103-106.

Motosugi, H., K. Okudo, D. Kataoka and T. Naruo. 2002b. Comparison of growth characteristics between diploid and colchicine-induced tetraploid grape rootstocks. J. Hort. Sci. 71: 335-341.

Motosugi, H. and Y. Yamamoto. 2000. The comparison of shoot growth, leaf morphology, and flow rate of bleeding sap between diploids and tetraploids of '3309' and 'Riparia Gloire' grape rootstocks. J. Japan. Soc. Hort. Sci. 69 (Suppl. 2): 112 (In Japanese).

Motosugi, H. and Y. Yamamoto. 2004. Water relation and net photosynthetic rates of leaves on 'Kyoho' grapevine grafted on tetraploid rootstocks. Bull. Exp. Farm Fac. Agri. Kyoto Pref. Univ. 24: 16-19.

Murashige, T. and F. Skoog. 1962. A revised medium for rapid growth and bioassays with tobacco tissue cultures. Plant Physiol. 15: 473-497.

Okamoto, G. and S. Imai. 1989. Promotion of seeded berry set of Pione grapes by restricting root zone. Sci. Rep. Fac. Agri. Okayama Univ. 56: 1-10 (In Japanese with English abstract).

Okamoto, G., M. Noda, S. Imai and T. Fujiwara. 1991. Effect of levels of fertilizer application on vine growth and fruit development of 'Kyoho' grape planted on a restricted rooting volume. Sci. Rep. Fac. Agri. Okayama Univ. 78: 27-33 (In Japanese with English abstract).

Okamoto, G., H. Tada, A. Suyama, Y. Hayashi and K. Hirano. 2001. Effect of shoot vigor on the development of transmitting tissue and pollen tube growth in pistils of tetraploid grape, cv. Pione. Vitis 40: 105-110.

Olmo, H. P. 1976. Grapes. p. 294-298. In: N. W. Simmond (ed.). Evolution of crop plants. Longman Group Limited, London.

Reynolds, A. G. and A. P. Naylor. 1994. 'Pinot noir' and 'Riesling' grapevines respond to water stress duration and soil waterholding capacity. HortScience 29: 1505-1510.

Sawano, I. 2001. Regulation of growth by restricting root zone of fruit trees. III. Root confinement culture of satsuma mandarin. Reg. Plant Growth Develop. 36: 173-177 (In Japanese).

Staudt, G. 1995. Some remarks on triploid grapevines. Vitis 34: 129-130.

Yamaguchi, D. and H. Motosugi. 2004. The growth and fruit quality of 'Kyoho' grapevines grafted on '3309', 'Riparia Gloire' rootstock and their tetraploids. J. Japan. Soc. Hort. Soc. 73 (Suppl. 2): 125 (In Japanese). 